\title{
Oxide Single-Crystal Surfaces: A Playground for Self-assembled Oxide Nanostructures
}

\begin{abstract}
Romain Bachelet *
Institut des Nanotechnologies de Lyon, Centre National de la Recherche Scientifique - UMR 5270, École Centrale de Lyon, Ecully, France
\end{abstract}

The different (structural and chemical) properties of oxide single-crystal surfaces that can be exploited for the growth of self-assembled oxide nanostructures are briefly reviewed. A large variety of nanostructures can be obtained, controlled by surface and interface structure and chemistry, which play a predominant role in their formation mechanisms at this nanometer scale. It is reminded that surface atomic order, surface steps, chemical terminations or heteroepitaxial strain can be used to generate various nanostructures such as nanodots, nanowires, nanostripes, with controlled size, morphology, and spatial ordering.

Keywords: oxide single-crystals, surface structure and chemistry, self-assembly, nanostructures, interface energy

\section{OPEN ACCESS}

Edited by:

Zorica Konstantinovic, Institute of Material Science of

Barcelona, Spain

Reviewed by:

Shikha Varma,

Institute of Physics, India

Hans Boschker,

Max Planck Institut für Festkörperforschung, Germany

*Correspondence:

Romain Bachelet romain.bachelet@ec-lyon.fr

Specialty section:

This article was submitted to Condensed Matter Physics,

a section of the journal

Frontiers in Physics

Received: 30 April 2016 Accepted: 15 August 2016 Published: 30 August 2016

Citation:

Bachelet R (2016) Oxide

Single-Crystal Surfaces: A Playground for Self-assembled Oxide

Nanostructures. Front. Phys. 4:36.

doi: 10.3389/fphy.2016.00036

\section{INTRODUCTION}

Oxides present a wide range of remarkable properties (from metal-insulator transitions to multiferroïcity) that lead to various competing devices such as sensitive sensors, non-volatile memories, low consumption transistors, energy harvesters, and transducers, etc. [1]. Functional oxide nanostructures can even exhibit enhanced or novel physical properties compared to their bulk counterparts, and are thus of great interest for future devices in various application fields. The ability to generate and control different nanostructures (even more complex) would lead to a larger range of physical properties, with a fine understanding of the correlations between the structures at the atomic and nanometer scale and their properties being a key point. Since applications mainly require integration of single-crystalline materials in thin film form, the progress in the elaboration and characterization techniques of epitaxial thin films and supported nanostructures, has been done and has allowed designing materials with an atomic-scale control. Although nanostructures can be designed by top-down approaches (e.g., [2-4]), its high cost and size limitations $(\sim 100 \mathrm{~nm})$ have made the low-cost bottom-up approaches involving selforganization processes attractive. This approach is still investigated, as confirmed by the numerous recent papers and the recent issue of MRS Bulletin dedicated to the fabrication of ordered patterns and nanostructures via self-organization [5]. However, the realization of oxide nanostructures is still much less advanced than metal and semiconductor nanostructures, certainly because of the structural and chemical complexity of functional oxides. This complexity of oxides may be an advantage, leading to a larger range of structural/chemical/electronic flexibility and accessible properties, with respect to metals and semiconductors. Indeed, the rich variety of iono-covalent complex oxide structures allows various surface and nanostructure self-assembling properties. The range of available mismatched oxide epitaxial heterostructures is wider than metals and semiconductors and that can therefore lead to many nanostructures through the modulation of interface structure and energy. The nanostructures formation through interface energy modulation is governed by many parameters in dissimilar structures such as the structural mismatch with 
the most favorable coincident site lattices (CSL), the epitaxial elastic strain, the plastic relaxation created by misfitaccommodation dislocations, with domain matching epitaxy (DME) reducing the global mismatch when the accommodation dislocations are periodic [6-8]. The 3D island growth relieved by epitaxial strain is scarcely observed in oxides in comparison to metals or semiconductors, such as the archetype case of $\mathrm{Si}_{1-\mathrm{x}} \mathrm{Ge}_{\mathrm{x}}$ growth on $\mathrm{Si}(001)$ surface $[9,10]$, probably because of the larger elastic constants in oxides compared to $\mathrm{Si}$ and III-V semiconductors (at least by a factor of two). The strainrelieved formation of $3 \mathrm{D}$ oxide epitaxial islands has been observed only very low-nanoscale islands (lower than $\sim 100 \mathrm{~nm}$ in diameter and a few nanometers in height) $[7,11,12]$. The formation of other nanostructures should be explained by more complex mechanisms taking into account all the above mentioned parameters, the structural anisotropy (driving diffusion anisotropy), the chemical ordering and stoechiometry, surface polarity, and the balance between thermodynamics and kinetic driven by diffusion to flux ratio (D/F) during growth [1315]. For instance, crystallization annealing of lattice mismatched oxides deposited by chemical solution (CSD) can lead to the formation of epitaxial nanoislands by solid state dewetting where the size, shape, and spatial ordering can be controlled through self-patterning [7, 12, 16-18]. It is also worth noting that some oxide nanocomposites of different structures can be formed by self-assembly through spinodal decomposition mechanisms, as the artificial multiferroic nanocomposites composed of a ferromagnetic spinel and ferroelectric perovskite [19-23]. Stencil masks or nanoporous polymeric layers can also be used as templates for the realization of periodic arrays of functional oxide nanodots or nanowires [3, 24-26]. Another example is the fabrication of oxide-semiconductor core-shell nanowires that can be elaborated by molecular beam epitaxy (MBE) [27]. In addition to these mechanisms, the chemical termination of single-crystalline perovskite oxide substrates has played a major role in the conducted epitaxial growth of high quality oxide films and nanostructures. The progress made to control the chemical termination by chemical and thermal treatments of the most used oxide single-crystal substrates, $\mathrm{SrTiO}_{3}(001)$ in particular $[28,29]$, has opened doors toward the control, enhancement and emergence of original physical properties [30-32], with the most famous example of the formation of a high-mobility two-dimension electron gas (2DEG) at the $\mathrm{LaAlO}_{3} / \mathrm{SrTiO}_{3}$ interface appearing only on the $\mathrm{TiO}_{2}$ termination of the $\mathrm{SrTiO}_{3}$ (001) surface [30]. In addition, we will see that self-assembly of the chemical terminations of (001)-oriented perovskite singlecrystals can also be used to generate different nanostructures. Here, it will be briefly reviewed how the structural and chemical surface properties of oxide single-crystalline substrates can be used to tailor oxide nanostructures involving some of these self-assembly processes. In particular, it will be enlightened that the atomic structural anisotropy, surface step ordering, selfassembled chemical terminations, and more generally interface energies, are key parameters for the design of nanostructures by preferential atomic diffusion, nucleation and crystallographic orientation. Some examples of nanostructures will be given such as self-organized nanodots, nanowires or nanostripes, with different functional oxides of different structures.

\section{SURFACE STRUCTURE: ANISOTROPY AND STEPS}

By nature, single-crystalline surfaces are structurally anisotropic due to the specific atomic ordering (see Figure 1A). Atomic rows corresponding to crystallographic directions of low Miller indexes are the most compact and thus with the strongest cohesion energy. This anisotropic atomic ordering of the surface leads to anisotropic atomic surface diffusion, governed by Ehrlich-Schwoebel (ES) barriers [33]. Values of anisotropic diffusion are still unknown, probably because of the structural complexity of oxides. However, the anisotropic diffusion is revealed by epitaxial growth or by annealing single-crystals where faceted edges can be discerned along the crystallographic directions of low Miller indexes at the surface. Similarly to the $90^{\circ}$ atomic step-edges of the well-known $\mathrm{Si}(001)$ surface [33], faceted atomic step-edges of hundreds of nanometers can be observed on oxide single-crystal surfaces, such as perovskite $\mathrm{SrTiO}_{3}(001)$ [29] and $\mathrm{SrTiO}_{3}(110)$ [34], and spinel $\mathrm{MgAl}_{2} \mathrm{O}_{4}(001)$ [35]. Similarly to surface facets of low energy (low Miller indexes) driven by thermodynamic processes (large $\mathrm{D} / \mathrm{F}$ ), elastic interactions and surface polarity reasons [36, 37], epitaxial nanoislands or nanopits can also exhibit faceted edges from tens to hundreds of nanometers along the lowindex crystallographic directions [17, 38]. The shape of the nanoislands (pyramidal, hut, or hexagonal) depends on the crystallographic orientation, symmetry, epitaxial strain, surface energy, polarity, etc. The atomic surface reconstructions, that may depend on the oxygen vacancy ratio (e.g., [36, 39, 40]), can be another key parameter to control, favorizing different nanostructures. These anisotropic surface properties have also be used to favor a lateral growth by preferential coarsening along the low index directions, that can lead to horizontal 1D nanowires assisted by epitaxial strain, as in the case of (011)oriented fluorite $\mathrm{Ce}_{1-\mathrm{x}} \mathrm{Gd}_{\mathrm{x}} \mathrm{O}_{2-\mathrm{y}}$ lateral nanowires grown by CSD

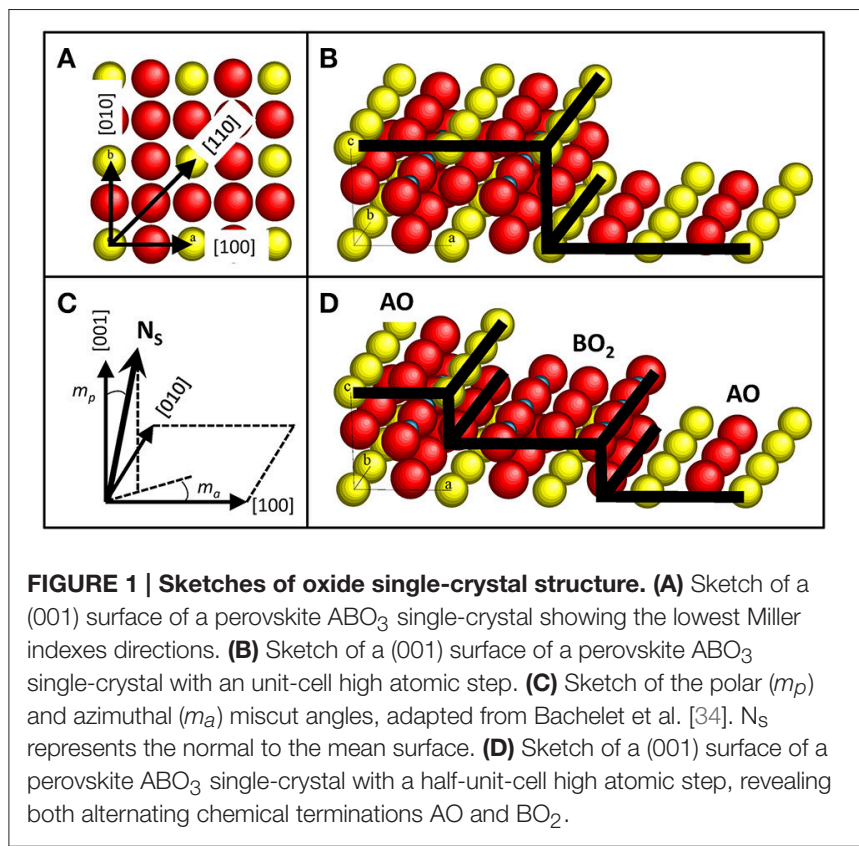


on $\mathrm{LaAlO}_{3}$ (001) surface, having dimensions of $\sim 20 \mathrm{~nm}$ in width and height and more than $1 \mu \mathrm{m}$ in length [41]. It is worth noting particular oxide materials with high energy anisotropy for which the growth along one direction is favored, naturally leading to $1 \mathrm{D}$ nanostructures, as the case of $\mathrm{ZnO}$ [42] and $\mathrm{WO}_{3}$ [43] for instance. The mean surfaces of single-crystals present atomic steps due to inevitable (polar and azimuthal) miscut angles because of the accuracy limitations of sample positioning during its cutting and polishing processes (see Figures 1B,C). The standard single-crystalline substrates have polar miscut angles lower than $0.3^{\circ}$, which corresponds to a unit-cell (uc) step every $75 \mathrm{~nm}$ at the $\mathrm{SrTiO}_{3}(001)$ surface for instance. Because of available specific substrates with different miscut angles that can be provided (from low 0.1 to $10^{\circ}$ ), the terrace width can be tuned from $\sim 250$ to $2.5 \mathrm{~nm}$. Surface steps are preferential nucleation sites (lowering the local free energy) and are anisotropic barriers for atomic surface diffusion [33]. As the step edges preferentially follow the low-index directions, the stepped surface morphology can be determined by the azimuthal miscut angle. Straight step edges will preferentially form on substrates with an azimuthal miscut angle along a low-index direction whereas "zigzag" steps will form when the azimuthal angle is off-low-index directions [34]. Since surface steps give rise to ES barriers for atomic diffusion, preferential alignment along the steps of epitaxial nanodots of $\sim 50 \mathrm{~nm}$ in diameter and less than $10 \mathrm{~nm}$ in height has been grown by preferential diffusion along the steps [44]. Also, as the surface atomic steps have an energetic cost (lower coordination sites), they will preferentially assemble together when the atomic surface diffusion will be larger than the mean terrace width, to form well-defined stable higher steps and wider terraces of lower energy (like surface facets of low Miller indexes). Almost-nominal atomically-flat surfaces can then be obtained by annealing on perovskite single-crystals like $\mathrm{SrTiO}_{3}(001)$ [29, 45, 46], $\mathrm{NdGaO}_{3}(001)$ [47], on sapphire [48], and on spinel $\mathrm{MgAl}_{2} \mathrm{O}_{4}(001)$ single-crystals [35] for instance. Similarly to semiconducting and metallic single-crystal surfaces, step bunching at oxide single-crystal surfaces can thus occur when increasing the polar miscut angle and/or annealing temperatures, leading to "hill and valley" surface nanostructures with periodicity of $\sim 80 \mathrm{~nm}$ and total height difference of $\sim 10 \mathrm{~nm}[7,9]$. In such a way, welldefined 1D surface nanostructures from faceted $10^{\circ}$-off vicinal $\alpha-\mathrm{Al}_{2} \mathrm{O}_{3}(0001)$ surfaces have been used for the realization of $1 \mathrm{D}$ well-ordered arrays of oxide nanodots of $\sim 35 \mathrm{~nm}$ in diameter and $\sim 8 \mathrm{~nm}$ in height through preferential $1 \mathrm{D}$ atomic surface diffusion in the valleys [7]. In the case of high miscut angles (high density of surface steps) and dissimilar heterostructures, the out-of-plane lattice mismatch existing between the film and a step of the substrate surface can lead to a crystallographic tilt, that can be written as follows: $\delta \omega=m_{p} \cdot \arctan \left(\mathrm{h}_{\mathrm{f}}-\mathrm{h}_{\mathrm{s}} / \mathrm{h}_{\mathrm{s}}\right)$, where $m_{p}$ is the polar miscut angle, $\mathrm{h}_{\mathrm{f}}$ and $\mathrm{h}_{\mathrm{s}}$ are the height of the steps of the film and the substrate, respectively [49]. Consequently, the morphology of the nanostructures and in particular the tilt of the crystal and its facets can be controlled by the density of surface steps via the polar miscut angle, as tilted YSZ (002) islands on highly vicinal sapphire surfaces $[7,50]$.

\section{SURFACE CHEMISTRY: ATOMIC TERMINATIONS}

In addition to structural anisotropy, single-crystal surfaces may have different chemical terminations, as it is the case with the (001)-oriented perovskite surfaces. Because of the inevitable miscut angle and the perovskite $\mathrm{ABO}_{3}$ structure, that can be seen as a periodic stack of $\mathrm{AO}$ and $\mathrm{BO}_{2}$ layers in the (001) direction, the epi-polished (001) surfaces of $\mathrm{ABO}_{3}$ single-crystals present both $\mathrm{AO}$ and $\mathrm{BO}_{2}$ terminations (see Figure 1D), that have motivated numerous studies from the 90's starting on the $\mathrm{SrTiO}_{3}$ (001) surface with the objective of controlling them for high-quality epitaxial oxide growth and realization of abrupt oxide heterointerfaces [28, 29, 45, 46]. This quest for the control of chemical termination in (001) single-crystal perovskite surfaces has followed with $\mathrm{LaAlO}_{3}$ [47], $\mathrm{NdGaO}_{3}$ [47], LSAT [51], and $\mathrm{DyScO}_{3}$ [52], and on layered $\mathrm{SrLaAlO}_{4}$ substrates $[53,54]$. Due to polishing effects, the as-received perovskite substrates have not well-defined step-and-terrace surfaces and contain both chemical terminations, which are mixed at the atomic scale and are difficultly distinguishable by atomic force microscopy (AFM) techniques [55]. Atomic surface diffusion reveals both chemical terminations by selfassembly with well-defined terraces separated by half-uc high steps and terraces of $\sim 150 \mathrm{~nm}$ wide depending of the miscut angle and the termination ratio in as-received substrates. This has been observed on $\mathrm{SrTiO}_{3}$ [56], on $\mathrm{LaAlO}_{3}$ [57], on $\mathrm{DyScO}_{3}$ [52], and on LSAT [11]. Surface potential differences between both terminations in $\mathrm{SrTiO}_{3}$ have been predicted to be around $2.3 \mathrm{eV}$ but measured with lower value [32]. These chemically-patterned surfaces have then been used to elaborate different nanostructures by selective growth (see Figure 2). Taking advantage of the termination-dependent chemical or energy properties (hydrophilic SrO termination in $\mathrm{SrTiO}_{3}$ for instance), a selective growth and adsorption of different materials such as $\mathrm{SrRuO}_{3}$, water, and organic tioles has been shown [29, $56,58]$. Ordered $1 \mathrm{D}$ nanostructures such as arrays of conducting $\mathrm{SrRuO}_{3}$ nanostripes (of the single-terminated terrace width) or nanodots $(\sim 70 \mathrm{~nm}$ wide and $\sim 4 \mathrm{~nm}$ high $)$ have then been realized in such a way on $\mathrm{LaAlO}_{3}$ [59], $\mathrm{SrTiO}_{3}[53,60]$, on $\mathrm{DyScO}_{3}[52,61]$, and on LSAT [11]. In the case of low energy interface, 2D epitaxial growth can occur without preferential nucleation with the chemical terminations replicating themselves at the film surface (see Figure 2A). In addition to the possible modulation of the properties in the out-of-plane direction with layered heterostructures elaborated by advanced deposition techniques, self-assembled chemical terminations have allowed to laterally modulate the interface and surface properties of heterostrucutres [32], generating for instance a $2 \mathrm{DEG}$ only at the specific $\left(\mathrm{LaO} / \mathrm{TiO}_{2}\right)$ laterally-confined regions on the singleterminated terrace width of the $\mathrm{LaAlO}_{3} / \mathrm{SrTiO}_{3}$ interface [62], as predicted [63]. More generally, that has allowed to study both chemical terminations of various functional perovskite oxides, such as ferromagnetic (La,Sr) $\mathrm{MnO}_{3}$ and ferroelectric $\mathrm{BaTiO}_{3}$, which are difficulty accessible even with advanced and widely used oxide deposition techniques such as pulsed laser deposition (PLD) [32]. The chemical terminations can also have a dramatic 


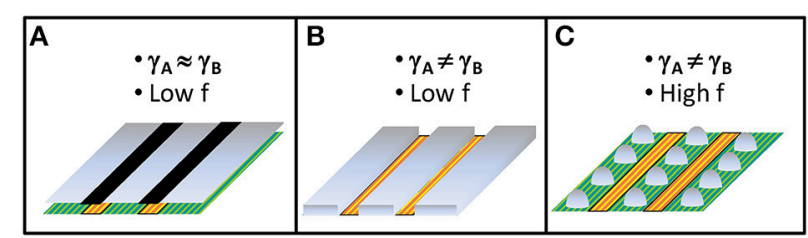

FIGURE 2 | Sketches of the different nanostructures that can be obtained on self-ordered chemical terminations of (001) surface of a perovskite $\mathbf{A B O}_{3}$ single-crystal. $f$ represents the lattice mismatch, $\gamma_{A}$ and $\gamma_{\mathrm{B}}$ represent the interfacial energies on $\mathrm{AO}$ and $\mathrm{BO}_{2}$ chemical terminations, respectively. (A) Replication of the chemical terminations by 2D growth in case of low interfacial energies and lattice mismatch. (B) Selective 2D growth only on one chemical termination due to different termination-dependent interfacial energies and low lattice mismatch. (C) Selective 3D growth only on one chemical termination due to different termination-dependent interfacial energies and high lattice mismatch.

effect on the crystallographic orientation and the morphology of thin films, as YSZ on $\mathrm{SrTiO}_{3}(001)$ surface where it has been shown that 2D growth of YSZ film only occurs on the SrO termination with (001)-orientation whereas dome-shaped tilted (111)-oriented YSZ islands of a few tens of nanometers in diameter and a few nanometers in height epitaxially grow on the $\mathrm{TiO}_{2}$ termination [64]. This observation has been explained by the differences in terms of chemical bonding and interfacial energies. However, specific energy values for these complex interfaces are tricky to determine and are still unknown.

\section{INTERFACE STRUCTURE AND ENERGY}

In addition to surface structure and chemistry, interface structure and energy play a particularly important role in the control of the shape of the epitaxial nanoobjects. Lattice mismatch (defined as $f=\left(\mathrm{a}_{\mathrm{s}}-\mathrm{a}_{\mathrm{f}}\right) / \mathrm{a}_{\mathrm{f}}$, where $\mathrm{a}_{\mathrm{s}}$ and $\mathrm{a}_{\mathrm{f}}$ are the in-plane lattice parameter of the substrate and the film, respectively) can generate elastic strain in heteroepitaxial nanostructures. Dissimilar epitaxial structures can thus have different possible structural matching at the interface, with different coincidence site lattices (CSL), and thus different interfacial energies. Epitaxial heterostructures with high interface energy will have tendency to minimize the interface whereas those with low interface energy will have tendency to maximize it [12]. For instance, in the case of dissimilar fluorite (YSZ) on sapphire (0001) surface, two epitaxial orientations can occur: (111) with low interface matching and (001) with domain interface matching reducing the lattice mismatch to $0.9 \%$. It has been observed that for YSZ epitaxial nanoislands grown by CSD, which is a thermodynamically driven growth (very large equivalent $\mathrm{D} / \mathrm{F}$ ), (111)-oriented nanoislands are dome-shaped with minimized interface area and (001)faceted surfaces, whereas (001)-oriented nanoislands are top-flat with larger interface area, in agreement with their structural matching and expected interface energy [7, 65]. Indeed, it has been shown that the ratio of (111)-oriented dome-shaped nanoislands can be increased by artificially increasing the substrate surface energy, through a soft deterioration of the epipolished substrate surface done by gentle scratching and further soft annealing leading to an enhancement of the density of surface steps [65]. Another example is the case of the epitaxial growth of $\mathrm{SrRuO}_{3}$ on chemically self-assembled LSAT (001) surface, where a selective growth on only one termination is also observed, similarly to deposition on chemically selfassembled $\mathrm{SrTiO}_{3}$ (001) surface, but forming in that case 1D arrays of nanodots by $3 \mathrm{D}$ growth instead of nanostripes by $2 \mathrm{D}$ growth (see Figures $\mathbf{2 B}, \mathbf{C}$ ). This difference can be explained by the lattice mismatch that is larger on LSAT $(-1.5 \%)$ than on $\mathrm{SrTiO}_{3}(-0.6 \%)$, although the epitaxial strain is in-plane compressive in both cases. The in-plane compressive strain can favor nanoislands formation, whereas in-plane tensile strain can favor nanopits formation, as shown in some epitaxial (La,Sr) $\mathrm{MnO}_{3}$ films grown on $\mathrm{SrTiO}_{3}$ (001) surface by sputtering [66]. Epitaxial growth of films with high surface energy may lead to $3 \mathrm{D}$ growth of nanostructures with surface facets of lower energy. That is the case with (001)-oriented spinel films, as ferromagnetic $\mathrm{CoFe}_{2} \mathrm{O}_{4}$, that tends to form nanopyramids with more stable (111) facets of lower surface energy at least by a factor of $5[67,68]$. That is also the case with (110)-oriented perovskite films, such as ( $\mathrm{La}, \mathrm{Sr}) \mathrm{MnO}_{3}$ that tend to form nanohuts with more stable (001) facets [65]. This thermodynamically driven tendency can be kinetically limited by decreasing the D/F ratio, or enhanced by increasing it, tuning the size of the nanoobjects $[13,15,69]$.

\section{CONCLUSIONS AND PROSPECTS}

In summary, oxide single-crystal surfaces can be well-exploited for the control of various nanostructures grown by selfassembly processes. We briefly reviewed that the size, shape, and spatial ordering of nanoobjects can be tailored by diverse properties and parameters of oxide single-crystal surfaces such as the structural symmetry, anisotropy and reconstructions, density and morphology of atomic steps tunable by polar and azimuthal miscut angles, chemical terminations that can self-order at the nanoscale, in-plane and out-ofplane lattice mismatches, epitaxial strain, interface energy. Furthermore, the diversity is vast regarding the panoply of elaboration techniques that can be used to drive the growth processes (balanced between thermodynamic and kinetic), leading then to different nanostructures. Novel strategies combining different materials and elaboration techniques can lead to biomimetic hybrid nanostructures with enhanced properties for microfluidic management, sensing, energy conversion, electronic, photonic, biomedical applications $[42,70-73]$.

\section{AUTHOR CONTRIBUTIONS}

The author confirms being the sole contributor of this work and approved it for publication.

\section{ACKNOWLEDGMENTS}

The topic editors are acknowledged for supporting this open-access publication. Flora Blom-Alvarez is gratefully acknowledged for the careful reading of the manuscript. 


\section{REFERENCES}

1. Ogale SB (ed.). Thin Films and Heterostructures for Oxide Electronics, New York, NY: Springer (2005).

2. Kim H, Bae C, Jung HS, Lee J-S, Shin H. Direct patterning of metal oxides by hard templates and atomic layer deposition. Int J Nanotechnol. (2010) 10:692-701. doi: 10.1504/IJNT.2013.054211

3. Nijland M, George A, Thomas S, Houwman EP, Xia J, Blank DHA, et al. Patterning of epitaxial perovskite from micro and nano molded stencil masks. Adv Funct Mat (2014) 24:6853-61. doi: 10.1002/adfm.201401170

4. Boes A, Sivan V, Ren G, Yudistira D, Mailis S, Soergel E, et al. Precise, reproductible nano-domain engineering in lithium niobate crystals. Appl Phys Lett. (2015) 107:022901. doi: 10.1063/1.4926910

5. Kang SH, Dickey MD (Guest Editors). Patterning via self-organization and self-folding. MRS Bull. (2016) 41:82-168. doi: 10.1557/mrs.2016.3

6. Narayan J, Larson BC. Domain epitaxy: a unified paradigm for thin film growth. J Appl Phys. (2003) 93:278-85. doi: 10.1063/1.1528301

7. Bachelet R, Cottrino S, Nahélou G, Coudert V, Boulle A, Soulestin B, Rossignol F, et al. Self-patterned oxide nanostructures grown by post-deposition thermal annealing on stepped surfaces. Nanotechnology (2007) 18:015301. doi: 10.1088/0957-4484/18/1/015301

8. Sánchez F, Bachelet R, de Coux P, Warot-Fonrose B, Skumryev V, Tarnawska $\mathrm{L}$, et al. Domain matching epitaxy of ferrimagnetic $\mathrm{CoFe}_{2} \mathrm{O}_{4}$ thin films on $\mathrm{Sc}_{2} \mathrm{O}_{3} / \mathrm{Si}(111)$. Appl Phys Lett. (2011) 99:211910. doi: 10.1063/1.3663216

9. Teichert C. Self-organization of nanostructures in semiconductor heteroepitaxy. Phys Reports (2002) 365:335-432. doi: 10.1016/S03701573(02)00009-1

10. Shchukin VA, Bimberg D. Spontaneous ordering of nanostructures on crystal surfaces. Reviews Mod Phys. (1999) 71:1125-71. doi: 10.1103/RevModPhys.71.1125

11. Bachelet R, Ocal C, Garzón L, Fontcuberta J, Sánchez F. Conducted growth of $\mathrm{SrRuO}_{3}$ nanodot arrays on self-ordered $\mathrm{La}_{0.18} \mathrm{Sr}_{0.82} \mathrm{Al}_{0.59} \mathrm{Ta}_{0.41} \mathrm{O}_{3}(001)$ surfaces. Appl Phys Lett. (2011) 99:051914. doi: 10.1063/1.3622140

12. Obradors X, Puig T, Gibert M, Queraltó A, Zabaleta J, Mestres N. Chemical solution route to self-assembled epitaxial oxide nanostructures. Chem Soc Rev. (2014) 43:2200-25. doi: 10.1039/c3cs60365b

13. Barth JV, Costantini G, Kern K. Engineering atomic and molecular nanostructures at surfaces. Nature (2005) 437:671-9. doi: 10.1038/nature04166

14. Hong W, Lee HN, Yoon M, Christen HM, Lowndes DH, Suo Z, et al. Persistent step-flow growth of strained films of vicinal substrates. Phys Rev Lett. (2005) 95:095501. doi: 10.1103/PhysRevLett.95.095501

15. Bachelet R, Pesquera D, Herranz G, Sánchez F, Fontcuberta J. Persistent two-dimensional growth of (110) manganite films. Appl Phys Lett. (2010) 97:121904. doi: 10.1063/1.3490713

16. Lange FF. Chemical solution routes to single-crystal thin films. Science (1996) 273:903-9. doi: 10.1126/science.273.5277.903

17. Langjahr PA, Wagner T, Rühle M, Lange FF. Thermally induced structural changes in epitaxial $\mathrm{SrZrO}_{3}$ films on $\mathrm{SrTiO}_{3}$. J Mater Res. (1999) 14:2945-51. doi: 10.1557/JMR.1999.0394

18. Szafraniak I, Harnagea C, Scholz R, Bhattacharyya S, Hesse D, Alexe M. Ferroelectric epitaxial nanocrystals obtained by a self-patterning method. Appl Phys Lett. (2003) 83:2211. doi: 10.1063/1.1611258

19. Zheng H, Wang J, Lofland SE, Ma Z, Mohaddes-Ardabili L, Zhao T, et al. Multiferroic $\mathrm{BaTiO}_{3}-\mathrm{CoFe}_{2} \mathrm{O}_{4}$ nanostructures. Science (2004) 303:661-3. doi: 10.1126/science.1094207

20. Zheng H, Zhan Q, Zavaliche F, Sherburne M, Straub F, Cruz MP, et al. Controlling self-assembled perovskite-spinel nanostructures. Nano Lett. (2006) 6:1401-7. doi: 10.1021/nl060401y

21. McManus-Driscoll JL. Self-assembled heteroepitaxial oxide nanocomposite thin film structures: designing interface-induced functionality in electronic materials. Adv Funct Mater. (2010) 20:2035-45. doi: 10.1002/adfm.201000373

22. Chen Y-J, Hsieh Y-H, Liao S-C, Hu Z, Huang M-J, Kuo W-C, et al. Strong magnetic enhancement in self-assembled mutliferroic-ferrimagnetic nanostructures. Nanoscale (2013) 5:4449-53. doi: 10.1039/c3nr00104k

23. Kim DH, Sun XY, Aimon NM, Kim JJ, Campion MJ, Tuller HL, et al. A three component self-assembled epitaxial nanocomposite thin film. Adv Funct Mat. (2015) 25:3091-100. doi: 10.1002/adfm.201500332
24. Vrejoiu I, Alexe M, Hesse D, Gösele U. Functional perovskites - From epitaxial films to nanostructured arrays. Adv Funct Mater. (2008) 18:1-15. doi: 10.1002/adfm.200800560

25. Carretero-Genevrier A, Puig T, Obradors X, Mestres N. Ferromagnetic 1D oxide nanostructures grown from chemical solutions in confined geometries. Chem Soc Rev. (2014) 43:2042-54. doi: 10.1039/c3cs60288e

26. Vila-Fungueirino JM, Bachelet R, Saint-Girons G, Gendry M, Gich M, Gazquez J, et al. Integration of functional complex oxide nanomaterials on silicon. Front Phys. (2015) 3:38. doi: 10.3389/fphy.2015.00038

27. Guan X, Becdelievre J, Meunier B, Benali A, Saint-Girons G, Bachelet R, et al. GaAs core / $\mathrm{SrTiO}_{3}$ shell nanowires grown by molecular beam epitaxy. Nano Lett. (2016) 16:2393-9. doi: 10.1021/acs.nanolett.5b05182

28. Kawasaki M, Takahashi K, Maeda T, Tsuchiya R, Shinohara M, Ishiyama O, et al. Atomic control of the $\mathrm{SrTiO}_{3}$ crystal surface. Science (1994) 266:1540-2. doi: 10.1126/science.266.5190.1540

29. Bachelet R, Sánchez F, Palomares FJ, Ocal C, Fontcuberta J. Atomically flat SrO-terminated $\mathrm{SrTiO}_{3}(001)$ substrate. Appl Phys Lett. (2009) 95:141915. doi: $10.1063 / 1.3240869$

30. Ohtomo A, Hwang HY. A high-mobility electron gas at the $\mathrm{LaAlO}_{3} / \mathrm{SrTiO}_{3}$ heterointerface. Nature (2004) 427:423-6. doi: 10.1038/nature02308

31. Lu H, Liu X, Burton JD, Bark CW, Wang Y, Zhang Y, et al. Enhancement of ferroelectric polarization stability by interface engineering. Adv Mater. (2012) 24:1209-16. doi: 10.1002/adma.201104398

32. Ocal C, Bachelet R, Garzón L, Stengel M, Sánchez F, Fontcuberta J. Nanoscale laterally modulated properties of oxide ultrathin films by substrate termination replica through layer-by-layer growth. Chem Mater. (2012) 24:4177-84. doi: 10.1021/cm302444s

33. Lagally MG, Zhang Z. Thin-film cliffhanger. Nature (2002) 417:907-10. doi: $10.1038 / 417907 a$

34. Bachelet R, Valle F, Infante IC, Sánchez F, Fontcuberta J. Step formation, faceting, and bunching in atomically flat $\mathrm{SrTiO}_{3}(110)$ surfaces. Appl Phys Lett. (2007) 91:251904. doi: 10.1063/1.2825586

35. Yanina SV, Carter CB. Terraces and ledges on (001) spinel surfaces. Surf Sci. (2002) 513:L402-12. doi: 10.1016/S0039-6028(02)01825-3

36. Noguera C. Polar oxide surfaces. J Phys Cond Matter. (2000) 12:R367-410. doi: 10.1088/0953-8984/12/31/201

37. Goniakowski J, Finocchi F, Noguera C. Polarity of oxide surfaces and nanostructures. Rep Prog Phys. (2008) 71:016501. doi: 10.1088/00344885/71/1/016501

38. Konstantinović Z, Sandiumenge F, Santiso J, Balcells L, Martínez B. Selfassembled pit arrays as templates for the integration of Au nanocrystals in oxide surfaces. Nanoscale (2013) 5:1001-8. doi: 10.1039/c2nr33181k

39. Kolpak AM, Li D, Shao R, Rappe AM, Bonnell DA. Evolution of the structure and the thermodynamic of the $\mathrm{BaTiO}_{3}(001)$ surface. Phys Rev Lett. (2008) 101:036102. doi: 10.1103/PhysRevLett.101.036102

40. Tselev A, Ganesh P, Qiao L, Siemons W, Gai Z, Biegalski MD, et al. Oxygen control of atomic structure and physical properties of $\mathrm{SrRuO}_{3}$ surfaces. ACS Nano (2013) 7:4403-13. doi: 10.1021/nn400923n

41. Gibert M, Abellán P, Benedetti A, Puig T, Sandiumenge F, García A, et al. Self-organized $\mathrm{Ce}_{1-x} \mathrm{Gd}_{x} \mathrm{O}_{2-y}$ nanowire networks with very fast coarsening driven by attractive elastic interactions. Small (2010) 6:2716-24. doi: 10.1002/smll.201001237

42. Yuan W, Lu Z, Li CM. Self-assembling microsized materials to fabricate multifunctional hierarchical nanostructures on macroscale substrates. J Mat Chem A (2013) 1:6416-24. doi: 10.1039/c3ta10704c

43. Vankova S, Zanarini S, Amici J, Camara F, Arletti R, Bodoardo S, et al. $\mathrm{WO}_{3}$ nanorolls self-assembled as thin films by hydrothermal synthesis. Nanoscale (2015) 7:7174-7. doi: 10.1039/c4nr07290a

44. Gibert M, Puig T, Obradors X, Benedetti A, Sandiumenge F, Hühne R. Self-organization of heteroepitaxial $\mathrm{CeO} 2$ nanodots grown from chemical solutions. Adv Mater. (2007) 19:3937-42. doi: 10.1002/adma.2007 00361

45. Koster G, Kropman BL, Rijnders GJHM, Blank DHA. Quasi ideal strontium titanate crystal surfaces through formation of strontium hydroxyde. Appl Phys Lett. (1998) 73:2920-2. doi: 10.1063/1.122630

46. Ohnishi T, Shibuya K, Lippmaa M, Kobayashi D, Kumigashira H, Oshima M, et al. Preparation of thermally stable $\mathrm{TiO}_{2}$-terminated $\mathrm{SrTiO}_{3}(100)$ substrate surfaces. Appl Phys Lett. (2004) 85:272-4. doi: 10.1063/1.1771461 
47. Ohnishi T, Takahashi K, Nakamura M, Kawasaki M, Yoshimoto M, Koinuma H. A-site layer terminated perovskite substrate: $\mathrm{NdGaO}_{3}$. Appl Phys Lett. (1999) 74:2531. doi: 10.1063/1.123888

48. Yoshimoto M, Maeda T, Ohnishi T, Koinuma H, Ishiyama, Shinohara M, et al. Atomic-scale formation of ultrasmooth surfaces on sapphire substrates for high-quality thin-film fabrication. Appl Phys Lett. (1995) 67:2615-7. doi: $10.1063 / 1.114313$

49. Nagai H. Structure of vapor deposited $\mathrm{Ga}_{x} \mathrm{In}_{1-x}$ As crystals. J Appl Phys. (1974) 45:3789. doi: 10.1063/1.1663861

50. Bachelet R, Nahélou G, Boulle A, Guinebretière R, Dauger A. Control of the morphology of oxide nano-islands through the substrate miscut angle. Prog Solid State Chem. (2005) 33:327-32. doi: 10.1016/j.progsolidstchem.200 5.11 .017

51. Ngai JH, Schwendemann TC, Walker AE, Segal Y, Walker FJ, Altman EI, et al. Achieving A-site termination on $\mathrm{La}_{0.18} \mathrm{Sr}_{0.82} \mathrm{Al}_{0.59} \mathrm{Ta}_{0.41} \mathrm{O}_{3}$ substrates. Adv Mater. (2010) 22:2945-8. doi: 10.1002/adma.200904328

52. Kleibeuker JE, Koster G, Siemons W, Dubbink D, Kuiper B, Blok JL, et al. Atomically defined rare-earth scandate crystal surfaces. Adv Funct Mat. (2010) 20:3490-6. doi: 10.1002/adfm.201000889

53. Becerra-Toledo AE, Marks LD. Strontium oxide segregation at $\mathrm{SrLaAlO}_{4}$ surfaces. Surf Sci. (2010) 604:1476-80. doi: 10.1016/j.susc.2010.05.011

54. Biswas A, Rossen PB, Ravichandran J, Chu Y-H, Lee Y-W, Yang C-H, et al. Selective A- or B-site single termination on surfaces of layered oxide SrLaAlO 4 . Appl Phys Lett. (2013) 102:051603. doi: 10.1063/1.4790575

55. Koster G, Rijnders G, Blank DHA, Rogalla H. Surface morphology determined by (001) single-crystal $\mathrm{SrTiO}_{3}$ termination. Phys $C$ (2000) 339:215-30. doi: 10.1016/S0921-4534(00)00363-4

56. Bachelet R, Sánchez F, Santiso J, Munuera C, Ocal C, Fontcuberta J. Self-assembly of $\mathrm{SrTiO}_{3}(001)$ chemical terminations: a route for oxide nanostructure fabrication by selective growth. Chem Mater. (2009) 21:2494-8. doi: $10.1021 / \mathrm{cm} 900540 \mathrm{z}$

57. Gunnarsson R, Kalabukhov AS, Winkler D. Evaluation of recipes for obtaining single terminated perovskite oxide substrates. Surf Sci. (2009) 603:151-7. doi: 10.1016/j.susc.2008.10.045

58. Paradinas M, Garzón L, Sánchez F, Bachelet R, Amabilino DB, Fontcuberta J, et al. Tuning the local frictional and electrostatic responses of nanostructured $\mathrm{SrTiO}_{3}$ surfaces by self-assembled molecular monolayers. Phys Chem Chem Phys. (2010) 12:4452-8. doi: 10.1039/b924227a

59. Vasco E, Dittman R. Karthäuser S, Waser R. Early self-assembled stages in epitaxial $\mathrm{SrRuO}_{3}$ on $\mathrm{LaAlO}_{3}$. Appl Phys Lett. (2003) 82:2497-9. doi: $10.1063 / 1.1566798$

60. He J, Dittman R, Karthäuser S, Vasco E. Geometric shadowing from rippled $\mathrm{SrRuO}_{3} / \mathrm{SrTiO}_{3}$ surface templates induces self-organization of epitaxial $\mathrm{SrZrO}_{3}$ nanowires. Phys Rev B (2006) 74:205410. doi: 10.1103/PhysRevB.74.205410

61. Kuiper B, Blok JL, Zandvliet HJW, Blank DHA, Rijnders G, Koster G. Selforganization of $\mathrm{SrRuO}_{3}$ nanowires on ordered oxide surface terminations. MRS Commun. (2011) 1:17-21. doi: 10.1557/mrc.2011.8

62. Foerster M, Bachelet R, Laukhin V, Fontcuberta J, Herranz G, Sánchez F. Laterally confined two-dimensional electron gases in self-patterned
$\mathrm{LaAlO}_{3} / \mathrm{SrTiO}_{3}$ interfaces. Appl Phys Lett. (2012) 100:231607. doi: $10.1063 / 1.4728109$

63. Bristowe NC, Fix T, Blamire MG, Littlewood PB, Artacho E. Proposal of a onedimensional electron gas in the steps at the $\mathrm{LaAlO}_{3}-\mathrm{SrTiO}_{3}$ interface. Phys Rev Lett. (2012) 108:166802. doi: 10.1103/PhysRevLett.108.166802

64. Cavallaro A, Ballesteros B, Bachelet R, Santiso J. Heteroepitaxial orientation control of YSZ thin films by selective growth on $\mathrm{SrO}-, \mathrm{TiO}_{2}$-terminated $\mathrm{SrTiO}_{3}$ crystal surfaces. Cryst Eng Comm. (2011) 13:1625-31. doi: 10.1039/c0ce00606h

65. Bachelet R, Boulle A, Soulestin B, Rossignol F, Guinebretière R, Dauger A. Two-dimensional versus three-dimensional post-deposition grain growth in epitaxial oxide thin films: Influence of the substrate surface roughness. Thin Solid Films (2007) 515:7080-5. doi: 10.1016/j.tsf.2007.02.099

66. Konstantinovic Z, Santiso J, Balcells L, Martínez B. Strain-driven selfassembled network of antidots in complex oxide thin films. Small (2009) 5:265-71. doi: 10.1002/smll.200800814

67. Lüders U, Sánchez F, Fontcuberta J. Self-organized structures in $\mathrm{CoCr}_{2} \mathrm{O}_{4}(001)$ thin films: tunable growth from pyramidal clusters to a $\{111\}$ fully faceted surface. Phys Rev B (2004) 70:045403. doi: 10.1103/PhysRevB.70.045403

68. Mishra RK, Thomas G. Surface energy of spinel. J Appl Phys. (1977) 48:4576-80. doi: 10.1063/1.323486

69. Dix N, Fina I, Bachelet R, Fábrega L, Kanamadi C, Fontcuberta J, et al. Large out-of-plane ferroelectric polarization in flat epitaxial $\mathrm{BaTiO}_{3}$ on $\mathrm{CoFe}_{2} \mathrm{O}_{4}$ heterostructures. Appl Phys Lett. (2013) 102:172907. doi: 10.1063/1.4803943

70. Huang J, Lai Y, Wang L, Li S, Ge M, Zhang K, et al. Controllable wettability and adhesion on bioinspired multifunctional $\mathrm{TiO}_{2}$ nanostructure surfaces for liquid manipulation. J Mater Chem A (2014) 2:18531-8. doi: 10.1039/c4ta04090b

71. Zhang S, Zhang P, Wang Y, Ma Y, Zhong J, Sun X. Facile fabrication of a wellordered porous $\mathrm{Cu}$-doped $\mathrm{SnO}_{2}$ thin film for $\mathrm{H}_{2} \mathrm{~S}$ sensing. ACS Appl Mater Interfaces (2014) 6:14975-80. doi: 10.1021/am502671s

72. Kawasaki S, Takahashi R, Yamamoto T, Kobayashi M, Kumigashira $\mathrm{H}$, Yoshinobu J, et al. Photoelectrochemical water splitting enhanced by self-assembled metal nanopillars embedded in oxide semiconductor photoelectrode. Nat Commun. (2016) 7:11818. doi: 10.1038/ncomms11818

73. Dudte LH, Vouga E, Tachi T, Mahadevan L. Programming curvature usinf origami tesselations. Nat Materials (2016) 15:583-8. doi: 10.1038/ nmat4540

Conflict of Interest Statement: The author declares that the research was conducted in the absence of any commercial or financial relationships that could be construed as a potential conflict of interest.

Copyright (C) 2016 Bachelet. This is an open-access article distributed under the terms of the Creative Commons Attribution License (CC BY). The use, distribution or reproduction in other forums is permitted, provided the original author(s) or licensor are credited and that the original publication in this journal is cited, in accordance with accepted academic practice. No use, distribution or reproduction is permitted which does not comply with these terms. 